(a) The development of surgical methods of treating congenital disorders of the heart.

(b) The discovery that in peripheral vascular disease the symptoms are sometimes due to a localized block involving a few inches of a main artery.

In congenital heart disease arterial homotransplants have been used successfully in the Blalock-Taussig type of operation when straightforward anastomosis was impossible without undue tension; and in the treatment of coaractation of the aorta, when the length of segment excised was too great for repair by end to end anastomosis. In peripheral arterial disease an occluded segment of artery may be excised and replaced by an autotransplant of vein or by an arterial homotransplant. The tissue of the homotransplants does not survive permanently but is slowly replaced by endothelium and connective tissue from the host.

Segments of arteries for transplantation are obtained at autopsy, preferably from young subjects with no trace of arterial disease. They may be used fresh but this is seldom convenient and several blood vessel banks have now been established. At the Boston Children's Hospital, Gross stores arterial transplants in a plasma-saline mixture. At. St. Mary's Hospital, Eastcott and Rob freeze the transplants quickly in liquid nitrogen and store them in glass tubes surrounded by carbon dioxide snow and kept in a deep freeze.

The technique of anastomosis is similar to that described by Carrel. Two stay sutures are inserted and one of these is continued as an everting continuous mattress suture. The danger of thrombosis is much less if heparin is administered postoperatively; the suturing must therefore be sufficiently accurate to permit this.

\section{Homotransplantation of Endocrine Tissues and Kidney}

The idea of treating patients with endocrine deficiencies or extensive irreparable renal damage by means of homotransplants is intriguing. Much experimental work has been done in this field but the results so far are disappointing, and despite the occasional claims of successful homotransplantation of the kidney by vascular anastomosis, and of suprarenal and parathyroid gland, these procedures must at present be regarded as dangerous and unlikely to succeed.

Will the problem of making homotransplants of endocrine and other tissues which are capable of surviving and functioning for an indefinite time ever be solved? Time alone will tell but present indications justify an attitude of cautious optimism. If a solution is found it should mean the beginning of a new era in the history of surgery.

\title{
SOME NOTES ON WILM'S TUMOUR
}

\author{
By G. L. Bunton, F.R.C.S.
}

Nephroblastoma is an uncommon growth, in spite of the fact that it accounts for a high proportion of malignant disease in childhood. It is known as Wilm's Tumour, although Gairdner first described it in 1828 .

It does not fall to the lot of the general surgeon to see many of these patients. Indeed only two have been admitted to the Westminster Children's Hospital during the last two years. Ladd and Gross, who have had as great experience as anyone of this condition, collected 54 cases from a large area of the United States of America. In adults it is very rare. Esersky collected 54 cases from the literature and added three of his own.

The recent admission to this hospital of a particularly rapidly growing tumour in a little girl aged five unexpectedly revealed sharply divergent views on treatment. The argument is an old one and has not yet run its course. It is irradiation versus surgery. Before the advent of irradiation the outlook was poor and, even since, few patients have been cured. Ladd and Gross report 13 survivors out of 54 patients, their life-span ranging from a few months to twenty-one years after treatment. They state that if there is recurrence, it is within the first 9 months in 95 per cent. of patients.

Until recently pre-operative irradiation was advised, sometimes followed by similar postoperative treatment. After three to five weeks a previously large mass might become operable and even impalpable; the risk of metastasis was said to be less during the disturbance of the operation. This is perhaps rather a vain hope as over half the patients have demonstrable metastases when first 
seen (Ockerblad, 1949). The greatest protagonist of irradiation alone was Dean in New York, who claimed 5 five-year survivals from 20 patients thus treated. But without the criterion of biopsy such success can be questioned. It is significant that he has now abandoned this method and has reverted to a combination of irradiation and surgery.

Lately opinion has changed, led chiefly by Higgins in this country and Ladd in America. They maintain that any delay even with irradiation prejudices the already slender hopes of recovery. The condition should be regarded as one of urgency and removal of the growth carried out as soon as the diagnosis has been made. Time will have to prove the wisdom of such a course. The immediate survival rate at the present time appears to be about 30 per cent. with either pre-operative or post-operative irradiation.

A generous paramedian incision gives adequate exposure, although oblique incisions are favoured by some surgeons. The first objective is to confirm the presence of the opposite kidney, next the renal vein should be tied as close to the vena cava as possible before any examination or handling of the affected kidney. This is a counsel of perfection. In a recent patient such a course was impossible and the kidney had to be mobilised first. When the pedicle was reached the vein was found flattened and stretched over the surface of the tumour affording hardly any lumen at all and being clear of growth. In this specimen the pathologist observed spread along the lymphatics at the periphery of the tumour, a path of dissemination perhaps not stressed enough.

Post-operative irradiation is started as soon as the wound is healed. Higgins advises only a short wait of seven to ten days, Ockerblad fears disruption of the wound at such an early stage and delays two to three weeks. Total body irradiation has been tried in addition to local treatment, others prefer that the chest should receive irradiation as well as the operation site. Certain dangers of irradiation must be mentioned. First, children do not take kindly to this form of treatment and may need careful nursing. Serial blood counts should be used to detect any leukopaenia. The bones too may suffer in structure and growth. Second, in girls the ovaries may receive a lethal dose but this risk may have to be accepted. Third, damage to the remaining kidney has been reported, chronic nephritis and hypertension may follow.

All in all we still cannot regard the treatment of this disease with any satisfaction.

The tumour from which the photograph was taken came from a girl aged five. It weighed 27 ounces and measured $13 \times 9 \times 9 \mathrm{cms}$. The kidney was perched on its upper lateral border and its

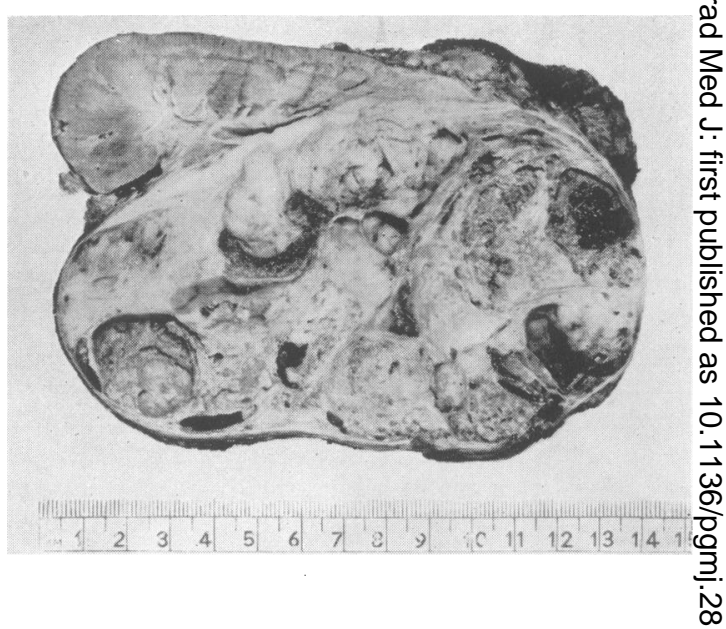

lower pole was compressed by the tumour with no capsule intervening.

The mass was composed of white friable tissue्త్ much of which was necrotic and haemorrhagico The renal pelvis and veins were not infiltrated by the growth nor was there any extension outside the capsule of the kidney.

The tumour showed two distinct varieties of cells. In one there was differentiation into an epithelial structure with tubule formation and attempt at the production of glomeruli-the " $p$ glomeruli.' In the other, the structure was 9 f non-differentiated cellular tissue giving no in dication of its origin. The smaller clumps of cells were seen to lie in spaces lined by a flat endo thelium. These spaces were dilated lymphatics This evidence of lymphatic spread is not a feature commonly mentioned in accounts of this tumouro It is more usual to find both epithelial tissue and the anaplastic cellular tissue intermingled, sug gesting foci of differentiation in an undiffer entiated field.

In this case, most of the tumour consisted of the anaplastic variety and only a small part was of the epithelial type, the latter being separated froms the rest of the tumour by a fibrous band.

I wish to thank Mr. David Levi for his help Dr. Miller for kindly cutting the sections and for his commentary on the pathological details of the tumour; and the Photographic Department of the Westminster Hospital for the photograph.

\section{BIBLIOGRAPHY}

GARDINER, E. (1828), Edin. M. Eீ S. F., 29, 312.

ESERSKY, G. L. (1947), $\mathcal{F}$. Urol., 58, 397. OCKERBLAD, N. F. (1949), Urology in General Practice,

DEAN, A. L. (1945), New York State Med. F., 45, 1213.

LADD, W. E., and GROSS, R. E. (1941), "Abdominal Surgery in Childhood,' W. B. Saunders, London and Philadelphia.

HIGGINS, T. T., WILLIAMS, D. I., and NASH, D.F.E. (195I)

'Urology in 'Childhood,' Butterworth, London. 